\title{
Cause and Predictors of Neonatal Mortality among Neonates admitted to Neonatal Intensive Care Units of Public Hospitals in eastern Ethiopia: Facilities based Prospective follow-up study
}

\author{
Assefa Desalew ( $\square$ assefad100@gmail.com ) \\ Yitagesu Sintayehu \\ Haramaya University College of Health and Medical Sciences \\ Nardos Teferi \\ Haramaya University College of Health and Medical Sciences \\ Firehiwot Amare \\ Haramaya University College of Health and Medical Sciences \\ Bifitu Geda \\ Haramaya University College of Health and Medical Sciences \\ Teshager Worku \\ Haramaya University College of Health and Medical Sciences \\ Kebebush Abera \\ Haramaya University College of Health and Medical Sciences \\ Abiyot Asefaw \\ Haramaya University College of Health and Medical Sciences
}

Haramaya University College of Health and Medical Sciences https://orcid.org/0000-0001-6065-0708

\section{Research article}

Keywords: Facilities based study, Neonatal mortality, predictors, NICU, Ethiopia

Posted Date: October 28th, 2020

DOl: https://doi.org/10.21203/rs.2.13233/v2

License: (a) This work is licensed under a Creative Commons Attribution 4.0 International License. Read Full License

Version of Record: A version of this preprint was published at BMC Pediatrics on April 14th, 2020. See the published version at https://doi.org/10.1186/s12887-020-02051-7. 


\section{Abstract}

Background: The first month is the most crucial period for child survival. Neonatal mortality is stagnated in sub-Saharan Africa including Ethiopia. And the trend in reduction is slower than infant and child mortality. The facilities-based cause and predictor of neonatal death in the neonatal intensive care unit were not well documented in this study setting. Hence the aim of this study was to determine the cause and predictors of neonatal mortality among neonates admitted in neonatal intensive care units in eastern Ethiopia.

Method: Facilities-based prospective follow-up study was conducted among neonates admitted in neonatal intensive care units of public hospitals in eastern Ethiopia from November to December 2018. Data were collected using pre-tested, structured questionnaire and follow-up checklist. The main outcomes, cause of death was set by senior pediatricians and residents. Epi-Data 3.1 and SPSS 25 version software were used for entry and analysis. Binary logistic regression was used to find out the predictors of facilities-based neonatal mortality.

Result: The proportion of facilities-based neonatal mortality was $20 \%$. The top five cause of death was a complication of prematurity $49 \%$, birth asphyxia $37.8 \%$, infection $32.6 \%$, meconium aspiration syndrome $17.3 \%$ and congenital malformation $6.1 \%$. Low birth weight, preterm births, length of stay, low $5^{\text {th }}$ minutes Apgar score, hyperthermia and initiation of feeding were predictors of neonatal death among Neonates admitted in neonatal intensive care units in public hospitals, eastern Ethiopia.

\section{Conclusion}

In summary, the proportion of facilities-based Neonatal death was unacceptably high. The main causes of death were preventable and treatable. Hence, early detection, anticipating high-risk newborns and timely intervention is very essential. Furthermore, early initiation of feeding and a better referral linkage to tertiary facilities could contribute for reduction of neonatal death in this setting.

\section{Background}

The first month is the most crucial period for child survival. Globally, an estimated 2.5 million newborn were died in the first month of life, approximately 7,000 every day in 2017 . Currently, an estimated 18 neonatal deaths per 1,000 live births occur in the neonatal period $[1,2]$. Neonatal death accounts for $46 \%$ of under-five mortality $[2,3]$. And about, $70 \%$ of these early neonatal deaths were due to conditions that could be prevented or treated with access to simple, affordable interventions[1,2,4-8].

Moreover, $98 \%$ of the above deaths occur in developing countries with the greater burden of deaths occurs and stagnated in subSaharan Africa (SSA). In this region, one million neonatal mortality occurs in the first month of life which had the highest neonatal mortality rate(NMR) among sustainable development goals(SDGs) regions and showing the least progress to the reducing of NMR $[1,3,6,9,10]$. Most of these deaths are caused by infectious diseases, intrapartum asphyxia, pregnancy-related complications and premature births[11].

Neonatal death still remains a significant public health problem in Ethiopia. In the last decade, NMR has a slower reduction, for example, 39 in 2008 to 29 in 2017 per 1000 live birth [12,13]. facilities-based study in Ethiopia (and) indicated that the proportion of neonatal death was $14.3 \%$ in Gondar and $23.3 \%$ Addis Ababa[13,14]. Despite many efforts by the government and other stakeholders, neonatal death remains higher than many developing countries[10]. Even though, the country is committed to achieving SDGs related both maternal and child health, which was clearly reflected in the Health Sector Development Program IV and the Health Sector Transformation program and working collaboration with World Health Organization (WHO) to improve the quality of neonatal intensive care units (NICU) in the health facilities, the reduction is still not well accelerated $[14,15]$.

Thus, rapid reduction in neonatal death is increasingly critical to progress towards achieving the SDGs. Therefore, determining the facilities-based causes and predictors of neonatal death in eastern Ethiopia context are very crucial and essential. Since the recent establishment of NICU in this setting, data are very limited both in the country and study setting. Hence, this facility based Prospective Follow- up study aimed to fill these gaps and used as inputs for policymakers and program implementers to design appropriate intervention that could contribute to the reduction of neonatal mortality and morbidity in the country.

\section{Methods}


This facility-based prospective follow-up study was conducted among all neonates admitted in NICU in eastern Ethiopia from November 1 to December 30, 2018. Public health facilities which have NICU setting in Harari regional state, Dire Dawa administration, and eastern and western harrarghe zone from Oromia regional state were included. These facilities have been providing health services for estimated 6,565,406 total populations in the catchment areas. A total of 10 public hospitals are currently providing care for a sick newborn in their NICU.

All neonates admitted in NICU during the study period were included from six public hospitals. Structured questionnaire and checklist which was adapted from different kinds of literature were used. The tool contains information related to obstetrics, ANC visit, age at admission, sex, and gestational age at birth, Apgar score, admission diagnosis, birth weight, and duration of hospital stay, the need of ventilator support, neonatal outcome and cause of death. It was prepared in English and translated to the local language then, re-translated back to English to ensure consistency and understandability.

Maternal and demographic data were obtained by interviewing the mother or reviewing referral record by neonatal nurses and each neonate was monitored daily until discharge or death. A final assessment of the cause of death was set by the pediatrician and residents after conducting the necessary laboratory investigation. In this study, any neonatal conditions or diagnosis identified for deceased neonates were considered as causes of death. In other words, causes of deaths were defined as the underlying neonatal conditions, which presented in the admitted of the deceased neonate.

Prematurity was described as live-birth newborn delivered before 37 completed weeks. For mothers who did not know dates of their last normal menstrual period, residents used ultrasound and the new Ballard score to estimate the gestational age. Birth weight was classified using WHO weight classification[16]. Birth weight was measured during admission using a digital infant weighing scale (Seca), which was placed on a fixed and leveled couch and enumerated for each newborn. Birth asphyxia was diagnosed whenever a newborn had an Apgar score $<7$ in the first or fifth minutes[17].

Twelve neonatal nurses, pediatric residents, and senior pediatricians had received refreshment trained intensively for two days about the purpose of the study, enumeration procedures, how to interview and follow-up of the neonates. Then the tool was pretested and necessary modifications were made to suit to local context prior to data collection. The principal investigators shared ethical issues and ways of addressing contingency management. Then, all completed questionnaires were checked for completeness and cleaned manually. After that, double data entry was done to check the clarity.

\section{Statistical Analysis}

The tool was coded and entered into EPI data version 3.1, and then exported to SPSS version 22 statistical software for analysis. Data were summarized and presented using descriptive statistics. The outcome variables were coded as " 1 " for died whereas " 0 " for improved. The association between the outcome variables (i.e. Neonatal death) and independent variables were analyzed using a binary logistic regression model. Covariates having a p-value $<0.2$ were retained and entered into the multivariable logistic regression analysis using forward stepwise approach. Hosmer and Lemeshow, goodness-of-fit test were used to assess whether the necessary assumptions were fulfilled. The results were presented as adjusted odds ratio (AOR) with $95 \%$ confidence intervals (Cl). A pvalue $<0.05$ was considered for declaring significant associated factors with the outcome variable.

Ethical clearance was obtained from the Institutional Health Research Ethics Review Committee in the College of Health and medical science, Haramaya University. Following the approval, an official letter of cooperation was given to the Region and City administration Health Bureau, zonal and Woreda health office and Hospitals. Then, permission was obtained from respective officials. The purpose and importance of the study were explained to the study participants and facilities heads. Overall, data were collected only after fully written informed consent was sought from each participant. All findings were kept confidential. The names and address of the participants were not recorded on the questionnaire.

\section{Results}

\section{Maternal Sociodmographic and ANC characteristics}

A total of 489 neonates were admitted in the study period. About 279 (57.1\%) mothers of the neonates were in the age group of 2130 years with a mean age of $26.44 \pm 6.04$ years. And 198 (40.5\%) were unable to read and write, while $452(90 \%)$ of the mothers were 
married moreover, more than half of 255(52.1\%) participants were an urban resident. Regarding ANC follow-up, two-third of mothers $378(77.3 \%)$ had attended ANC at least once but only $116(23.7 \%)$ were received the recommended follow up for the current pregnancy. Around 180(36.8\%) of mothers, started ANC follow up before 24 weeks of gestation (Table 1).

Table 1: Characteristics of mothers of neonates who were admitted to NICU of public hospitals in eastern Ethiopia, 2018[n=489].

\begin{tabular}{|c|c|c|c|}
\hline Characteristics & Category & Frequency & Percent \\
\hline \multirow[t]{4}{*}{ Age } & less than 20 years & 109 & 22.3 \\
\hline & $21-30$ years & 279 & 57.1 \\
\hline & $31-40$ years & 95 & 19.4 \\
\hline & $\geq 41$ years & 6 & 1.2 \\
\hline \multirow[t]{5}{*}{ Education level } & Unable to read and write & 198 & 40.5 \\
\hline & Able to read and write & 59 & 12.1 \\
\hline & Primary Education & 111 & 22.7 \\
\hline & Secondary Education & 80 & 16.4 \\
\hline & College and above & 41 & 8.4 \\
\hline \multirow[t]{4}{*}{ Marital status } & Single & 28 & 5.7 \\
\hline & Married & 452 & 92.4 \\
\hline & Divorced & 7 & 1.4 \\
\hline & Widowed & 2 & 0.4 \\
\hline \multirow[t]{2}{*}{ Residence } & Urban & 255 & 52.1 \\
\hline & Rural & 234 & 47.9 \\
\hline \multirow[t]{2}{*}{ ANC follow-up } & Yes & 378 & 77.3 \\
\hline & No & 111 & 22.7 \\
\hline \multirow[t]{2}{*}{ Place of ANC follow up } & Public & 320 & 65.4 \\
\hline & Private & 58 & 11.9 \\
\hline \multirow[t]{4}{*}{ Gestational age at the start of ANC follow up } & $<24$ wks & 180 & 36.8 \\
\hline & $24-29$ wks & 149 & 30.5 \\
\hline & 30- 35 wks & 37 & 7.6 \\
\hline & greater than $35 w k s$ & 12 & 2.5 \\
\hline \multirow[t]{4}{*}{ Number of ANC follow up attended } & One & 37 & 7.6 \\
\hline & Two & 80 & 16.4 \\
\hline & Three & 145 & 29.7 \\
\hline & four and above & 116 & 23.7 \\
\hline
\end{tabular}

\section{Obstetrics characteristics}

The majority, 283(57.9\%) of neonates were from multi-Para mothers. Ninety percent of the neonates were delivered as a singleton and 380 (77.7\%) were delivered at the index Hospitals. Regarding birth attendants, 299(61.1\%) were midwives, about 288(58.9\%) of mothers had a labor duration ranging 4-12 hours. In addition, more than two-thirds 338(69.1\%) of the deliveries were through spontaneous vaginal delivery and 319(65\%) of neonate were birth at term gestation (Table 2).

Table 2: Obstetrics characteristics of mothers with their neonates who were admitted to NICU of public hospitals in eastern Ethiopia, 2018[n=489]. 


\begin{tabular}{|c|c|c|c|}
\hline Characteristics & Category & Frequency & Percent \\
\hline \multirow[t]{2}{*}{ Parity } & Primipara & 206 & 42.1 \\
\hline & Multipara & 283 & 57.9 \\
\hline \multirow[t]{2}{*}{ Type of pregnancy } & Single & 440 & 90.0 \\
\hline & Twins & 49 & 10.0 \\
\hline \multirow[t]{5}{*}{ Place of delivery } & At the index Hospital & 380 & 77.7 \\
\hline & Another hospital & 30 & 6.1 \\
\hline & Health center & 53 & 10.8 \\
\hline & Private facilities & 4 & 0.8 \\
\hline & Home & 22 & 4.5 \\
\hline \multirow[t]{6}{*}{ Birth attendant } & Midwife & 299 & 61.1 \\
\hline & Physician & 151 & 30.9 \\
\hline & Nurse & 11 & 2.2 \\
\hline & HEWS & 2 & 0.4 \\
\hline & TBA & 23 & 4.7 \\
\hline & Others & 3 & 0.6 \\
\hline \multirow[t]{3}{*}{ Duration of labor } & $<4 \mathrm{hrs}$ & 43 & 8.8 \\
\hline & 4-12hrs & 288 & 58.9 \\
\hline & Greater than 12 hrs. & 158 & 32.3 \\
\hline \multirow[t]{3}{*}{ Amniotic fluid status during labor } & Clear & 360 & 73.6 \\
\hline & Meconium stained & 107 & 21.9 \\
\hline & Bloodstained & 22 & 4.5 \\
\hline \multirow[t]{3}{*}{ Mode of delivery } & Spontaneous Vaginal & 338 & 69.1 \\
\hline & Cesarean section & 122 & 24.9 \\
\hline & Instrumental Delivery & 29 & 5.9 \\
\hline \multirow[t]{3}{*}{ Gestational age at birth } & Pre-term & 160 & 32.7 \\
\hline & Term & 319 & 65.2 \\
\hline & Post term & 10 & 2.0 \\
\hline \multirow[t]{3}{*}{ Length of hospital stay } & $<3$ days & 160 & 32.7 \\
\hline & $4-7$ & 229 & 46.8 \\
\hline & $>7$ & 100 & 20.4 \\
\hline
\end{tabular}

\section{Complications during pregnancy}

Only $81(16.6 \%)$ of mothers had a complication during the current pregnancy. From those complications, preeclampsia or eclampsia $43(8.8 \%)$ was the commonest one. In addition, about 30(6.1\%) mothers were suffered from Medical illness during pregnancy. Nearly half $226(46.2 \%)$ of the mothers had a complication during labor and the most common complication $103(21.1 \%)$ were prolonged duration of labor (Table 3).

Table 3: distribution on complications during current pregnancy and labor among mothers of neonates admitted to NICU of public Hospitals in eastern Ethiopia, $2018[n=489]$. 


\begin{tabular}{|c|c|c|c|}
\hline Characteristics & Category & Frequency & Percent \\
\hline \multirow[t]{7}{*}{ Obstetric complications during current pregnancy } & Yes & 81 & 16.6 \\
\hline & No & 408 & 83.4 \\
\hline & Preeclampsia or eclampsia & 43 & 8.8 \\
\hline & Chorioamnionitis & 8 & 1.6 \\
\hline & Premature rupture of membrane & 18 & 3.7 \\
\hline & Ant partum hemorrhage & 17 & 3.5 \\
\hline & Other & 1 & 0.2 \\
\hline \multirow[t]{9}{*}{ Medical illness during pregnancy } & Yes & 30 & 6.1 \\
\hline & No & 459 & 93.9 \\
\hline & Diabetes mellitus & 5 & 1.0 \\
\hline & Hypertension & 8 & 1.6 \\
\hline & Tuberculosis & 1 & 0.2 \\
\hline & Cardiac disease & 1 & 0.2 \\
\hline & Anemia & 14 & 2.9 \\
\hline & Human immunodeficiency virus & 3 & 0.6 \\
\hline & Others & 2 & 0.4 \\
\hline \multirow[t]{6}{*}{ Complication during labor } & Yes & 226 & 46.2 \\
\hline & No & 263 & 53.8 \\
\hline & Prolonged labor & 103 & 21.1 \\
\hline & Premature rupture of membrane & 62 & 12.7 \\
\hline & Fetal distress & 84 & 17.2 \\
\hline & Cord prolapsed & 8 & 1.6 \\
\hline
\end{tabular}

\section{Neonatal Characteristics}

The majority, 306(62.6\%) were male and more than three- fourth 378 (77.3\%) were admitted within the first day of life. More than half $274(56.4 \%)$ of the neonates had a Normal birth weight (2500-3999grams). More than two-thirds 350(71.6\%) of the neonates were hypothermic upon admission, around $35(27.2 \%)$ of neonates have suffered from birth asphyxia at $5^{\text {th }}$ minute and $301(61.1 \%)$ were initiated exclusive breastfeeding (Table 4).

Table 4: Neonatal characteristics among neonates admitted to NICU of public Hospitals in eastern Ethiopia, 2018[n=489]. 


\begin{tabular}{llll}
\hline Variable & Category & Frequency & Percent \\
\hline Sex of the newborn & Male & 306 & 62.6 \\
& Female & 183 & 37.4 \\
Age of neonate on admission & $\leq$ one day & 378 & 77.3 \\
& $>$ one days & 111 & 22.7 \\
Birth weight & $<1000$ grams & 8 & 1.6 \\
& 1000-1499 grams & 33 & 6.7 \\
& $1500-2499$ grams & 145 & 29.7 \\
& $2500-3999$ grams & 274 & 56.0 \\
Temperature at admission $\left({ }^{0} \mathrm{C}\right)$ & $<36.5$ & 29 & 5.9 \\
& $36.5-37.5$ & 350 & 71.6 \\
& $>37.5$ & 42 & 18.8 \\
Score at Apgar 5 ${ }^{\text {th }}$ minutes & $\leq 3$ & 7 & 9.6 \\
& $4-6$ & 126 & 1.4 \\
& $7-10$ & 251 & 51.3 \\
Initiation of Feeding & Unknown & 105 & 21.5 \\
& NPO & 152 & 31.1 \\
& EBF & 301 & 61.1 \\
& Formula Feeding & 36 & 7.4 \\
\hline
\end{tabular}

\section{Treatment modalities}

Nearly, 435 (89\%) of neonates have received antibiotics and Intravenous fluids $416(85.1 \%)$ as main treatment while only $72(14.7 \%)$ were utilizing the kangaroo mother care (figure 1).

\section{The proportion of Neonatal death}

Among admitted newborn, $98(20 \%)$ died and the majority of death occurs in the first day of life. the remaining were survived and discharged (Figure2).

\section{Cause of Neonatal Mortality}

Regarding the cause of death, the most common causes were prematurity $48(49 \%)$ followed by birth asphyxia $37(37.8 \%)$ and infection 32(32.6\%) among neonates admitted in NICU as shown in (Figure3).

\section{Predictors of Neonatal death}

In the multivariate logistic analysis, low $5^{\text {th }}$ minutes Apgar score, low birth weight, preterm birth, length of hospital stay, being febrile and feeding status were independent predictors of neonatal mortality. Being preterm was almost three times more likely to die as compared with term neonates (AOR, 2.78 [95\% Cl: 1.17, 6.57]). Low birth weight babies were about two times more likely to die when compared with normal birth weight (AOR, 2.39 [95\% Cl: 1.04, 5.41]). Furthermore, neonates with low $5^{\text {th }}$ minutes Apgar score was five times more likely die as compared with $5^{\text {th }}$ minutes APGAR score of greater than or equal to seven (AOR, 5.18[95\% Cl: 2.51, 10.66]); length of staying was another variable found to be predictors of mortality(AOR,3.63 [95\% Cl:1.82, 7.22]), Neonates stayed for less than 3 days were more likely die than those who stayed 4-7 days, this implied that majorities of deaths occurred in the first 72 hours of life. In addition, neonates with fever at admission were seven times more likely to die as compared with the normal temperature at admission (AOR, 6.68 [95\% Cl: 1.34, 33.13]). Moreover, neonates who have not initiated feeding in the first 24 hours were about twelve times more likely to die than those were initiated with exclusively breastfeeding (AOR, 12.16 [95\% Cl: 5.98, 24.70]) and found to be significant predictors of neonatal mortality (Table 5). 


\begin{tabular}{|c|c|c|c|c|c|}
\hline \multicolumn{6}{|l|}{ Neonatal mortality } \\
\hline Characteristics & Died & Improved & COR & $\mathrm{AOR}$ & P value \\
\hline \multicolumn{6}{|l|}{ Maternal Age } \\
\hline $21-30$ years & 51 & 228 & 1 & & \\
\hline$<20$ years & 29 & 80 & $1.62(0.96,2.73)$ & $1.50(0.67,3.34)$ & - \\
\hline $31-40$ years & 17 & 78 & $0.97(0.53,1.78)$ & $1.85(0.76,4.48)$ & \\
\hline$>40$ years & 1 & 5 & $0.89(0.102,7.818)$ & $2.40(0.23,24.89)$ & \\
\hline \multicolumn{6}{|l|}{ Marital status } \\
\hline Married & 88 & 364 & 1 & 1 & \\
\hline Single & 9 & 19 & $1.96(0.86,4.48)$ & $1.33(0.35,5.03)$ & \\
\hline Others & 1 & 8 & $0.52(0.06,4.18)$ & $1.62(0.15,16.94)$ & - \\
\hline \multicolumn{6}{|l|}{ Parity } \\
\hline Multi-Para & 50 & 233 & 1 & 1 & \\
\hline Primi-para & 48 & 158 & $1.42(0.91,2.21)$ & $1.94(0.93,4.05)$ & - \\
\hline \multicolumn{6}{|l|}{ Place of delivery } \\
\hline Inborn (in this hospital) & 253 & 127 & 1 & 1 & \\
\hline Other facility & 46 & 41 & $0.56(0.29,1.09)$ & $0.50(0.17,1.51)$ & \\
\hline Home & 16 & 6 & $0.35(0.08,1.53)$ & $0.26(0.03,2.40)$ & - \\
\hline \multicolumn{6}{|l|}{ Duration of labor } \\
\hline $4-12 \mathrm{hrs}$ & 177 & 111 & 1 & 1 & \\
\hline less than $4 \mathrm{hrs}$ & 27 & 16 & $0.80(0.35,1.81)$ & $0.45(0.12,1.63)$ & - \\
\hline More than $12 \mathrm{hrs}$ & 111 & 47 & $0.69(0.41,1.14)$ & $0.62(0.30,1.25)$ & \\
\hline \multicolumn{6}{|l|}{ Mode of delivery } \\
\hline Spontaneous vaginal & 221 & 117 & 1 & 1 & \\
\hline Cesarean section & 79 & 43 & $1.23(0.73,2.05)$ & $1.00(0.47,2.10)$ & - \\
\hline Instrumental & 15 & 14 & $2.78(1.24,6.17)$ & $1.34(0.40,4.44)$ & \\
\hline \multicolumn{6}{|c|}{ Length of hospital stay } \\
\hline 4-7 days & 172 & 57 & 1 & 1 & \\
\hline$<3$ days & 68 & 92 & $4.03(2.43,6.67)$ & $3.63(1.82,7.22){ }^{*}$ & .000 \\
\hline$>7$ days & 75 & 25 & $0.77(0.35,1.63)$ & $0.61(0.23,1.58)$ & \\
\hline \multicolumn{6}{|c|}{ Gestational age at birth } \\
\hline Term & 227 & 92 & 1 & 1 & \\
\hline Preterm & 82 & 78 & $3.56(2.23,5.66)$ & $2.78(1.17,6.56)^{*}$ & .020 \\
\hline Post term & 6 & 4 & $4.65(1.25,17.19)$ & $4.54(0.83,24.70)$ & \\
\hline \multicolumn{6}{|l|}{ Birth weight } \\
\hline 2500-3999 grams & 211 & 86 & 1 & 1 & \\
\hline Less than 2499 grams & 77 & 86 & $3.46(2.17,5.49)$ & $2.39(1.04,5.49)^{*}$ & .040 \\
\hline$\geq 4000$ grams & 27 & 2 & $0.23(0.03,1.73)$ & $0.67(0.06,6.80)$ & \\
\hline \multicolumn{6}{|l|}{ APGAR at $5^{\text {th }}$ minutes } \\
\hline $7-10$ & 188 & 63 & 1 & 1 & \\
\hline$\leq 6$ & 68 & 65 & $5.62(3.32,9.47)$ & $5.18(2.51,10.66) *$ & .000 \\
\hline Unrecorded & 59 & 46 & $1.33(0.67,2.60)$ & $2.50(0.82,7.54)$ & \\
\hline \multicolumn{6}{|c|}{ Temperature on admission } \\
\hline $36.5-37.5 \mathrm{c}^{0}$ & 64 & 28 & 1 & 1 & \\
\hline$<36.5 \mathrm{c}^{0}$ & 218 & 132 & $3.37(1.56,7.23)$ & $2.75(0.97,7.78)$ & \\
\hline$>37.5 \mathrm{c}^{0}$ & 33 & 14 & $1.25(0.38,4.05)$ & $6.68(1.345,33.13)$ * & *.020 \\
\hline \multicolumn{6}{|l|}{ Initiation of Feeding } \\
\hline EBF & 237 & 64 & 1 & 1 & \\
\hline NPO & 53 & 99 & $16.71(9.32,29.94)$ & $12.16(5.98,24.70)$ * & $* .000$ \\
\hline FF & 25 & 11 & $2.69(0.930,7.80)$ & $1.71(0.47,6.15)$ & \\
\hline
\end{tabular}


*statistically significant at $\mathrm{p} \leq 0.05$

\section{Discussion}

The finding of the present study indicated that the proportion of neonatal death was $20 \%$. The main cause of death was a complication of prematurity $49 \%$, birth asphyxia $37.8 \%$, infection $32.6 \%$, MAS $17.3 \%$, RDS $16.1 \%$ and congenital malformation $6.1 \%$. In the multivariate logistic analysis, low $5^{\text {th }}$ minutes Apgar score, low birth weight, preterm births, length of stay, being febrile and feeding status were independent predictors of neonatal death among Neonates admitted in NICU of public hospitals in eastern Ethiopia.

This finding is in agreement with studies conducted in Ethiopia and developing countries like $18.69 \%$ in India, $20.2 \%$ in Eastern Nepal, 20.3\% -18.8\% in Nigeria and 23.3\% in Central Ethiopia[7,18-22]. However, it is greater than the studies carried out in Northern Vietnam 13.9\%, in India 7.16\%, in Ghana 16\%, in South Africa 13.8\%, and in Cameroon 15.7\%[5,23-26]. This difference in the proportion of death could be explained by the related factors for each study and discrepancy in the quality of care delivered through those studies setting.

With regard to the main causes of death, the present finding revealed that a complication of prematurity $49 \%$, birth asphyxia $37.8 \%$, infection $32.6 \%$, MAS $17.3 \%$, RDS $16.1 \%$ and congenital malformation $6.1 \%$ were found as the main cause of death. This was supported by findings from WHO, Northern Vietnam, India, Ghana, Nigeria, Cameroon, South Sudan, and southern and northern Ethiopia[5,11,18-20,23,24,25,27-30]. This causal agreement clearly indicated that neonatal survival interventions should target the intrapartum as well as immediate and early neonatal periods.

Intrapartum, neonatal conditions and immediate neonatal care practices were the most important predictors of neonatal death in the present study. Birth asphyxia, Prematurity, low birth weight and not initiating feeding early were found to increase the likelihood of neonatal death by five times, nearly three times, two times and about twelve times respectively. These findings are consistent with other previous studies in Ethiopia and different countries, in which the intrapartum and neonatal conditions were found to be the important predictors of neonatal mortality $[21,26,28,30-33]$. This may be explained by the fact that premature and low birth weight baby was more likely to be prone for complications like hypothermia, infections, and birth asphyxia (result in tissue hypoxia and multi-organ failure). So that, provision of quality neonatal care including, quality resuscitation, thermal care, and appropriate feeding important to avert some of these factors significantly [34-37].

Furthermore, short duration, less than 3 days of life at NICU was found significantly associated with neonatal death. This is in contrast, to study in the Somali region; a short stay in the NICU was protective against mortality. However, it consistent with the established fact that most of the neonatal deaths occur in the first 72 hours following birth, and any intervention at this critical time has a significant contribution to saving the life of neonates[38,40]. In addition, neonates with fever $\left(\geq 37.5^{\circ} \mathrm{C}\right)$ at admission are significantly found to be predictors of neonatal mortality. This might be due to a high proportion of infection in the present study setting.

Strength of this study was its multi facilities inclusion and neonates were prospectively followed from admission to discharge or death. In addition, it was carried out without sampling; hence it is used for eliminating any possible sampling error. However, its relatively small number study subject and some variables mentioned in the multivariate model had wide Cls which may undermine the strength of this study. Another limitation is that the follow up was restricted from admission to discharge; hence, this article does not reflect population-based neonatal mortality rather, it reflects the institution based neonatal death.

\section{Conclusion}

In conclusion, the proportion of facilities-based Neonatal mortality was unacceptably high. Five common causes of neonatal death were prematurity, birth asphyxia, infection, respiratory morbidity, and congenital malformation. Preterm births, low birth weight, low $5^{\text {th }}$ minutes APGAR score, short duration in NICU, Not early initiation of feeding and temperature $\left(\geq 37.5^{\circ} \mathrm{C}\right)$ at demission were significant predictors of mortality in eastern Ethiopia. Hence early detection, anticipating high-risk newborns and timely interventions are very essential. Furthermore, early initiation of feeding and a better referral linkage to tertiary facilities could contribute for reduction of neonatal mortality and morbidity in this setting. 


\section{Abbreviations}

ANC: Antenatal Care

AOR: Adjusted Odd Ratio

APGAR: Appearance, Pulse, Grimace, Activities, and Respiration

Cl: Confidence Interval

CSA: Central Statistical Agency

EBF: Exclusive Breast Feeding

MAS: Meconium Aspiration Syndrome

NICU: Neonatal Intensive Care Unit

NMR: Neonatal Mortality Rate

RDS: Respiratory Distress Syndrome

SDG: Sustainable Development Goal

SPSS: Statistical Package for Social Sciences

UNICEF: United Nations International Children's Emergency Fund

WHO: World Health Organization

\section{Declarations}

\section{Ethics approval and consent to participate}

Ethical clearance was obtained from the Institutional Health Research Ethics Review Committee College of health and medical science, Haramaya University. Following the approval, a written official letter of cooperation was given to the regional health Bureaus and facilities. Informed written consent was sought from the participants. Furthermore, confidentiality was assured throughout the process.

\section{Availability of data and materials}

All the data of this study are available from the corresponding author upon request.

\section{Consent to publish}

Not applicable

\section{Conflict of interest}

The authors declare that they have no conflicts of interest.

\section{Funding}

The authors disclosed receipt of the financial support from Haramaya University, Ethiopia.

\section{Author contributions}

A.D., Y.S., and N.T. designed the study, performed the statistical analysis and drafted the manuscript. B.G. and F.A. and participated in the study design and statistical analysis. T.W., K.A, and A. involved in the inception of the study. All authors contributed, read and 
approved the final version of the manuscript.

\section{Acknowledgment}

We would like to thank Haramaya University, research and project affairs for financial and unreserved technical support. Then, we also thank the health Bureau, hospital heads and the study participants for collaborations.

\section{Authors' information}

${ }^{1}$ School of Nursing and Midwifery College of Health and Medical Sciences, Haramaya University, Harar, Ethiopia

${ }^{2}$ School of Medicine, College of Health and Medical Sciences, Haramaya University, Harar, Ethiopia

${ }^{3}$ School of Pharmacy, College of Health and Medical Sciences, Haramaya University, Harar, Ethiopia

\section{References}

1. UNICEF, WHO WB \&UN. Levels and Trends in Child Mortality - Report 2018 Estimates developed by the UN Inter-agency Group for Child Mortality Estimation [Internet]. New York USA: UNICEF; 2018. p. 8-48. Available from: https://data.unicef.org/wpcontent/ uploads/2018/10/Child-Mortality-Report-2018.pdf.

2. WHO. WHO | Child mortality [Internet]. 2016. Available from: http://www.who.int/ maternal_child_adolescent/topics/child/mortality/en/

3. Oza S, Lawn JE, Hogan DR, Mathers C, Cousens SN. Neonatal cause-of-death estimates for the early and late neonatal periods for 194 countries: 2000-2013. Bull World Health Organ [Internet]. 2015;93(1):19-28.

4. Ali SR, Ahmed S, Lohana H. Disease patterns and outcomes of neonatal admissions at a secondary care hospital in Pakistan. Sultan Qaboos Univ Med J. 2013;13(3):418-21.

5. UNICEF, WHO, World Bank U-DPD. Levels and trends in child mortality [Internet]. New York: 2015. Available from: http://www.who.int/maternal_child_adolescent /documents/levels_trends_child_mortality.

6. Omoigberale Al., Sadoh WE, Nwaneri DU. A 4-year review of neonatal outcome at the University of Benin Teaching Hospital, Benin City. Niger J Clin Pract. 2010;13(3):321-5.

7. Seoud I, El-din RMG, Said RN, Hessin HA. Predictors of Neonatal Mortality in Intensive Care Unit in Children's Hospital. Alexandria J Pediatr. 2005;19(1):93-7.

8. Mekonnen, Biruk Tensou, Daniel S Telake TD and AB. Neonatal mortality in Ethiopia: trends and determinants. BMC Public Heal 2013, 2013;13:471-83.

9. ICF CSA (CSA) [Ethiopia] and. Ethiopia Demographic and Health Survey 2016: Key Indicators Report. Addis Ababa, Ethiopia, and Rockville Maryland, USA.CSA and ICF; 2016.

10. WHO |. WHO | Newborn death and illness [Internet]. Geneva 27, Switzerland: WHO Press, World Health Organization; 2011. Available from: http://www.who.int/ pmnch/ media/press_materials/fs/fs_newborndealth_illness/en/.

11. World Bank. Ethiopia Neonatal mortality rate, World Development Indicators, The World Bank 1960-2017 [Internet]. 2018. Available from: https://knoema. com/atlas /Ethiopia/Neonatal-mortality-rate.

12. World Bank. World Development. Washington, DC: World Bank.: License: Creative Commons Attribution CC BY 3.0; 2013. p. 26.

13. Demisse AG, Alemu F, Gizaw MA, Tigabu Z. Patterns of admission and factors associated with neonatal mortality among neonates admitted to the neonatal intensive care unit of University of Gondar Hospital, Northwest Ethiopia. Pediatr Heal Med Ther. 2017;8:57-64.

14. Bogale Worku, Assaye Kassie, Amha Mekasha, Birkneh Tilahun AW. Predictors of early neonatal mortality at a neonatal intensive care unit of a specialized referral teaching hospital in. Ethiop J Heal Dev. 2012;26(3):200-7.

15. FMOH. Federal Democratic Republic of Ethiopia Ministry of Health: Health Sector Development Programme IV 2010/11 2014/15 [Internet]. Vol. IV. 2010. p. 114. Available from: http://www.nationalplanningcycles.org/sites/default/files/country_docs/Ethiopia/ethiopia_hsdp_iv_final_draft_2010_-2015.pdf 
16. WHO. Every Newborn Progress Report May 2015 [Internet]. Geneva 27, Switzerland: WHO Press, World Health Organization, 20 Avenue Appia; 2015. Available from: www. everynewborn.org\%0Awww.everynewborn.org

17. World Health Organization. Promoting Optimal Fetal Development [Internet]. GGENEVA, Switzerland: World Health Organization; 2006. p. 3-8. Available from: http://www. who. int/nutrition/topics/fetal_dev_report_EN.pdf

18. WHO. Guidelines on Basic Newborn Resuscitation [Internet]. World Health Organization. WHO Press, World Health Organization, 20 Avenue Appia, 1211 Geneva 27, Switzerland; 2012. Available from: https://www.who.int/ maternal_child_adolescent/. /basi C_newborn_resuscitation/en/

19. Prasad V S. Causes of morbidity and mortality in neonates admitted in Government Medical College,Haldwani in Kumaun Region(Uttarakhand)India. J Pharm Biomed Sci. 2011;8(8):1-4.

20. Shah GS, Yadav S, Thapa A SL. Clinical Profile and Outcome of Neonates Admitted to Neonatal Intensive Care Unit (NICU) at a Tertiary Care Centre in Eastern Nepal. J Nepal Paediatr Soc. 2013;4(3):1511-6.

21. Elizabeth Ike U.and MOO. Pattern of Diseases and Care Outcomes of Neonates Admitted in. IOSR J Nurs Heal Sci Ver I [Internet]. 2015;4(3):2320-1940. Available from: www.iosrjournals.org

22. Tekleab A.M., Amaru GM, and TYA. Reasons for admission and neonatal outcome in the neonatal care unit of a tertiary care hospital in Addis Ababa: a prospective study. Res Reports Neonatol. 2016;6(2016):17-23.

23. Ndombo PK, Ekei QM, Tochie JN, Temgoua MN, Angong FTE, Ntock FN, et al. A cohort analysis of neonatal hospital mortality rate and predictors of neonatal mortality in a sub-urban hospital of Cameroon. Ital J Pediatr [Internet]. 2017;43(1):52.

24. Miles M, Dung KTK, Ha LT, Liem NT, Ha K, Hunt RW, et al. The cause-specific morbidity and mortality, and referral patterns of all neonates admitted to a tertiary referral hospital in the northern provinces of Vietnam over a one year period. PLoS One. 2017;12(3):1-12.

25. P. V. Sridhar PS TMS. Morbidity Pattern and Hospital Outcome of Neonates Admitted in a Tertiary Care Teaching Hospital, Mandya. Mymensingh Med J [Internet]. 2015;18 (2): 136-41. Available from: http://ovidsp.ovid.com/ovidweb.cgi.

26. Walana W., Acquah Ekuban KS., Abdul-Mumin A., Naafu B., Aruk E., Vicar Kofi E. KS, and ZBJ. Clinics in Mother and Child Health Pattern , Causes and Treatment Outcomes of Neonatal Admission in the Tamale Teaching Hospital. Clin Mother Child Heal. 2016;13(4):1000252.

27. Hoque M, Haaq S, Islam R. Causes of neonatal admissions and deaths at a rural hospital in KwaZulu-Natal, South Africa. South African J Epidemiol Infect 2011 [Internet]. 2011;26(1):26-9. Available from: http://www.sajei.co.za/index.php...

28. Dawal S., Inamdar I.F., Sudhir S.., Mohan D. ST an. PS. Study of Profile and Outcome of the Newborns Admitted in Neonatal Intensive Care Unit (NICU) at Tertiary Care Hospital in a City of Maharashtra. Int J Heal Sci Res. 2015;5(October 2015):18-23.

29. Kokeb M, Desta T. Institution Based Prospective Cross-Sectional Study on Patterns of Neonatal Morbidity at Gondar University Hospital Neonatal Unit, North-West Ethiopia. Ethiop J Health Sci [Internet]. 2016;26(1):73-9.

30. Thomson J, Schaefer M, Caminoa B, Kahindi D, Hurtado N. Improved Neonatal Mortality at a District Hospital in Aweil, South Sudan. J Trop Pediatr [Internet]. 2016; Jun; 63(3):189-195.

31. Debelew GT, Afework MF, Yalew AW. Determinants and causes of neonatal mortality in Jimma Zone, Southwest Ethiopia: A multilevel analysis of prospective follow up study. PLoS One. 2014;9(9).

32. Kang G, Lim JY, Kale AS, Lee LY. Adverse effects of young maternal age on neonatal outcomes. Singapore Med J. 2015;56(3):157-63.

33. Mengesha HG, Sahle BW. Cause of neonatal deaths in Northern Ethiopia: a prospective cohort study. BMC Public Health [Internet]. 2017;17(62):1-8.

34. Orsido TT, Asseffa NA and, Berheto TM. Predictors of Neonatal mortality in Neonatal intensive care unit at referral Hospital in Southern Ethiopia: A retrospective cohort study. BMC Pregnancy Childbirth. 2019;19(1):1-9.

35. Liu KC, Joseph J a., Nkole TB, Kaunda E, Stringer JS a, Chi BH, et al. Predictors and pregnancy outcomes associated with a newborn birth weight of $4000 \mathrm{~g}$ or more in Lusaka, Zambia. Int J Gynecol Obstet. 2013;122(2):150-5.

36. Abdallah Y, Namiiro F, Mugalu J, Nankunda J, Vaucher Y, McMillan D. Is facility-based neonatal care in low resource setting keeping pace? A glance at Uganda's National Referral Hospital. Afr Health Sci. 2016;16(2):347-55. 
37. Dassah ET, Odoi AT, Opoku BK. Stillbirths and very low Apgar scores among vaginal births in a tertiary hospital in Ghana: a retrospective cross-sectional analysis. BMC Pregnancy Childbirth [Internet]. 2014;14(1):289.

38. Hedstrom A, Ryman T, Otai C, Nyonyintono J, McAdams RM, Lester D, et al. Demographics, clinical characteristics and neonatal outcomes in a rural Ugandan NICU. BMC Pregnancy Childbirth [Internet]. 2014;14(1):327.

39. Seid SS, Ibro SA, Ahmed AA, Olani Akuma A, Reta EY, Haso TK, et al. Causes and factors associated with neonatal mortality in Neonatal Intensive Care Unit (NICU) of Jimma University Medical Center, Jimma, South West Ethiopia. Pediatr Heal Med Ther. 2019;10(2019):39-48.

40. Abdifatah EF., Abdulahi HA. and AT. Trends of admission and predictors of neonatal mortality: A hospital-based retrospective cohort study in the Somali region of. PLoS One. 2018;13(9):e0203314.

\section{Figures}

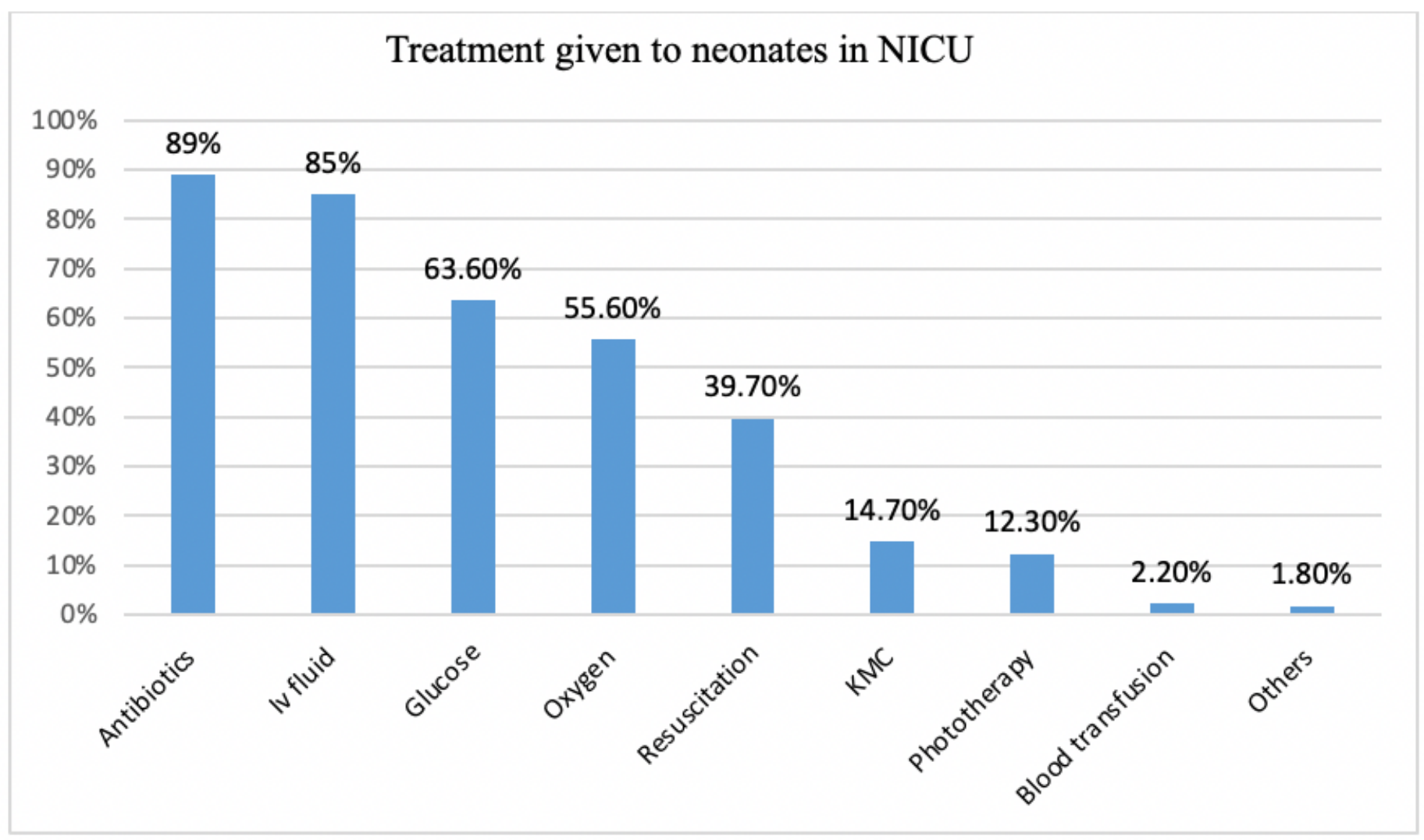

\section{Figure 1}

Treatment modalities delivered to neonates admitted to NICU of public Hospitals in eastern Ethiopia, 2018[n=489]. 


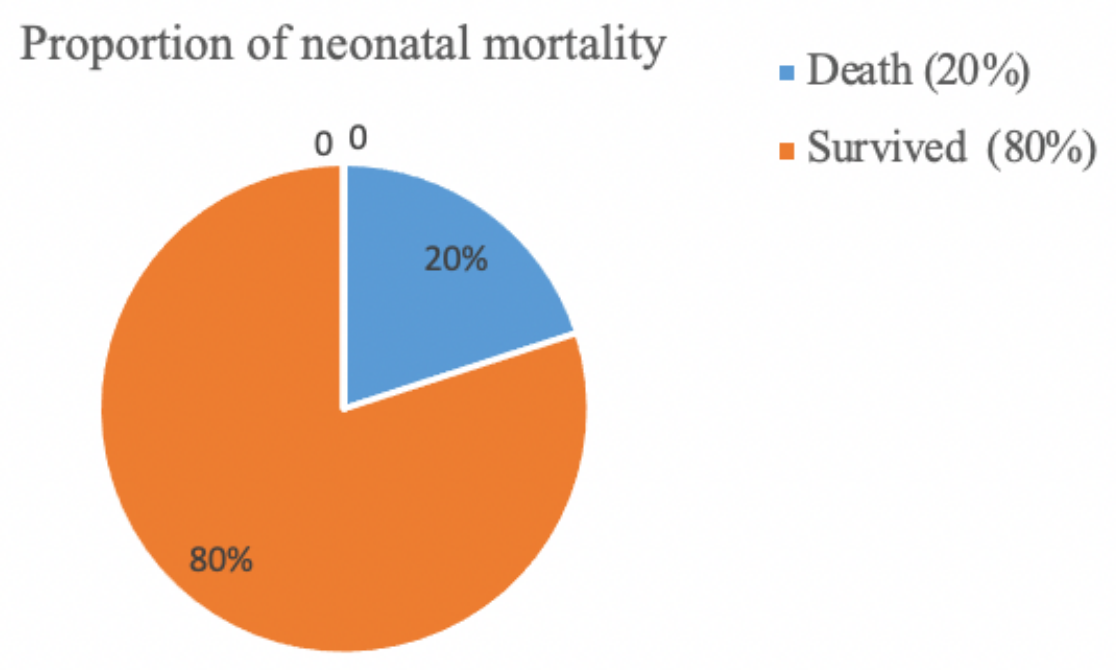

\section{Figure 2}

Proportion of neonatal death among neonates admitted to NICU of public Hospitals in eastern Ethiopia, 2018[n=489].

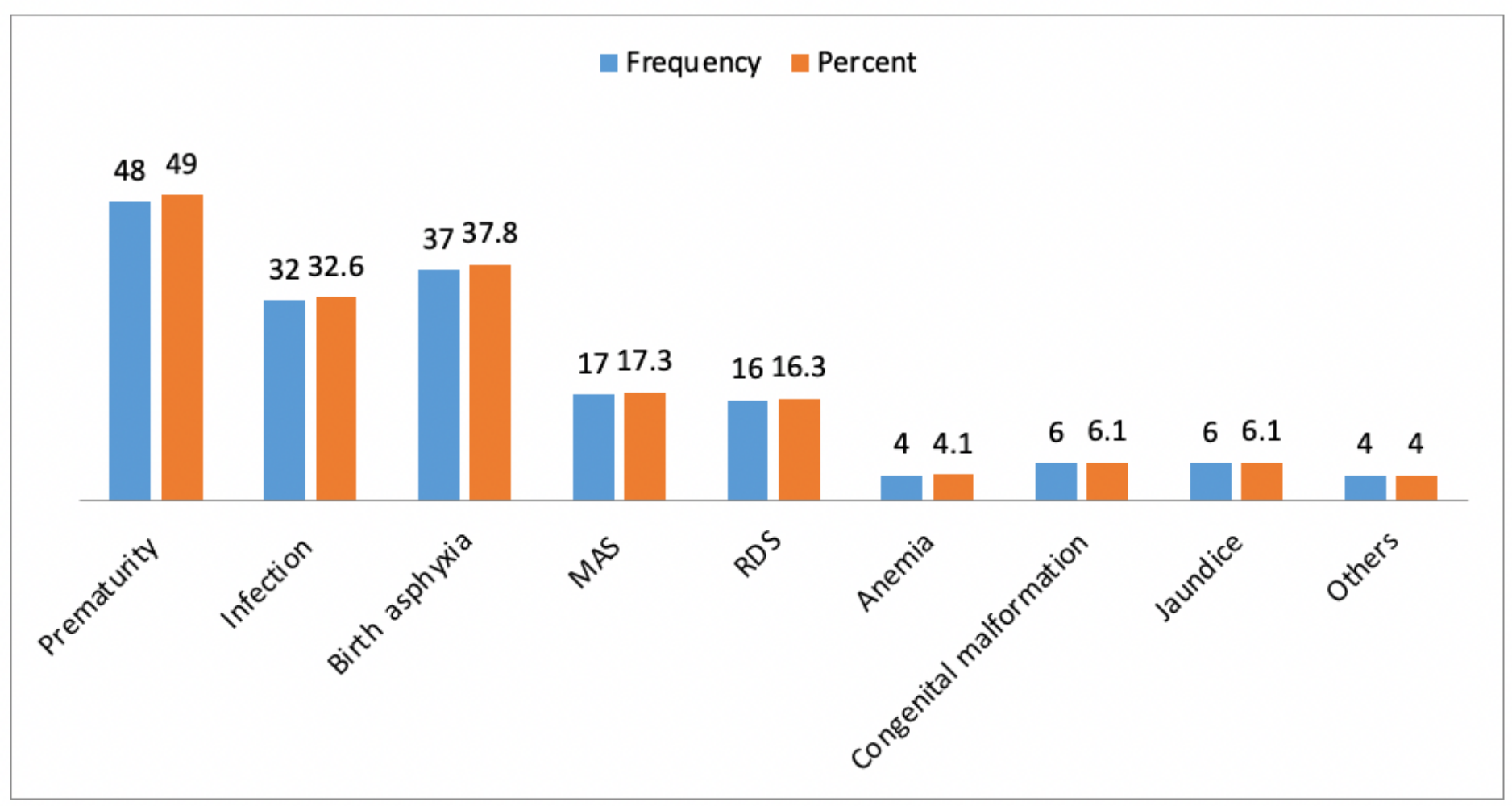

Figure 3

Cause of Neonatal Mortality among neonates admitted to NICU of public hospitals in eastern Ethiopia 2018[n=489]. 